\title{
The Effect of a Core Training Program Applied on Football Players on Some Performance Parameters
}

\author{
Ahmet Atlı (Corresponding Author) \\ School of Physical Education and Sport, Iğdır University, Turkey \\ Tel: 90-476-223-0010_E-mail: atliahmett@gmail.com
}

Received: April 5, 2021 Accepted: May 9, $2021 \quad$ Published: May 14, 2021

doi:10.5296/jei.v7i1.18493 URL: https://doi.org/10.5296/jei.v7i1.18493

\begin{abstract}
In this study, it was aimed to examine the effect of a core training program that was applied on football players on some performance parameters. In total, 40 football players, aged between 18 and 24 years old, who regularly trained in football and were from various amateur football teams participated: 20 athletes in the training group and 20 athletes in the control group. It was taken the pre-test measurements of the athletes' vertical jump, 30-m speed, agility, and flexibility; after the 6-week core training program, which was applied three days a-week, and it was taken the post-test measurements of the athletes. The training group applied the core training in addition to football training for 6-week, whereas the participants in the control group did not apply any training program other than their ongoing football training. It was used the SPSS 22 statistics program to evaluate the data and Shapiro-Wilk test to determine the normality distribution of the data. Owing to the normal distribution of the data, it was used a paired t-test to compare the pre-test and post-test values within the groups and accepted the confidence interval for statistical processes as $p<0.05$. It was found a statistically significant difference in the vertical jump pre-test and post-test values of the training group $(p<0.05)$. In the control group, there was no statistically significant difference in the vertical jump pre-test and post-test values $(\mathrm{p}>0.05)$. It was found a statistically significant difference in the $30-\mathrm{m}$ speed pre-test and post-test values of the training group ( $\mathrm{p}$ $<0.05)$. In the control group, there was no statistically significant difference in the $30-\mathrm{m}$ speed pre-test and post-test values $(\mathrm{p}>0.05)$. It was found a statistically significant difference in the agility pre-test and post-test values of the training group $(p<0.05)$. In the control group, no statistically significant difference was found in the agility pre-test and post-test values $(\mathrm{p}>0.05)$. Considering the in-group flexibility pre-test and post-test comparisons, a statistically significant difference was found in the flexibility pre-test and post-test values of the training group $(p<0.05)$. In the control group, there was no statistically significant difference in flexibility pre-test and post-test values $(p>0.05)$. Based
\end{abstract}


on the results of the present research, the 6-week core training program that was applied to football players improved the performance of vertical jump, 30-m speed, agility, and flexibility.

Keywords: Agility, Core training, Flexibility, Speed, Vertical jump

\section{Introduction}

Football, which requires high physical performance when done professionally, is considered one of the most popular sports in the world. This causes players in all positions to have numerous high-level motoric features (Akyüz et al., 2016; Köklü et al., 2009). Research on improving football performance mainly focuses on physical properties such as strength, speed and endurance, as well as technical and tactical features (Köse \& Atl1, 2020). In addition, there are various complex basic movements in football such as walking, running, sprinting, dribbling, shooting, and passing (Boyle, 2004; Eniseler, 1994); displaying these parameters with a high performance provides great advantages to the teams and players (Tatlic1 et al., 2018). Players with high-level technical and tactical skills can be successful if their basic motor skills are systematically developed (Ünlü \& Tatlıc1, 2018).

Strength is defined as a motoric feature that determines efficiency in numerous branches of sports. Strength and other motoric features have been stated to be mutually interacting processes, and the strength requirement level is different for every sports branch (Turna, 2020). For example, children generally perform strength exercises using their body weights (Muratl1, 2007). Increasing muscle strength provides an important advantage to athletes in almost all sports branches. As a result of scientific research on increasing muscle strength, various training methods have been recently developed. One such method is the core training method (McGill, 2010).

Core training applied by football players to increase their strength performance is known as the most applied training method. In this direction, core training has been used frequently in recent years as an effective method in training programs (Riewald, 2003). Because the muscles in the core region are located in the center of the body, they play an active role in the majority of body movements (Sato \& Mokha, 2009). Core training, which supports the spine and plays an active role in the integrity of muscle groups that are effective in upper extremity strength development, is defined as a new training method, especially in terms of performance development (Parkhouse \& Ball, 2011; Stanton et al., 2004). Core training is also known as a training method that allows for the strength development of the muscles in the lumbopelvic hip region, which are involved in core stability, with movements made with body weight (Akman et al., 2013; Clark, 2001). Core training is generally preferred to improve an individual's balance, strength, anatomical function, and flexibility (Sun et al., 2016). Further, while core training leads to positive structural changes in the muscles, it also supports neural adaptation. In addition, core training increases basic stability and strength by improving the proprioceptive senses and providing muscle development and body control (Iacono et al., 2014).

Core strength and core stabilization are not used in the same sense. While the stabilization of 
the spine occurs with the activation of the core muscles and creates the stabilization of the core, the force that occurs in the internal abdominal pressure by the contraction of the core muscles is called the core strength (Faries \& Greenwood, 2007). A developed core region allows athletes to withstand the training load to a greater extent and perform technical movements more efficiently. The upper extremity muscles in the core region are a considerably effective factor during the struggle that takes place in a football match (Handzel, 2003; Schiffer et al., 2008). With the development of the core region, the driving force of the upper extremity increases even more (Afyon, 2014; Saeterbakken et al., 2011). In this regard, in addition to basic training for soccer players, core training is emphasized to balance extremity strength (Dello et al., 2016). Given the aforementioned aspects, we aim to examine the effect of a 6-week core training program that was applied on football players on some performance parameters.

\section{Method}

\subsection{Participants}

In total, 40 football players, with ages ranging from 18 to 24 years old, who regularly trained in football and were from various amateur football teams participated in the study. There were 20 athletes in the training group (mean age, $21.13 \pm 1.41$ years; mean height, $174.29 \pm 7.62 \mathrm{~cm}$; mean body weight, $70.38 \pm 4.57 \mathrm{~kg}$; and mean training age, $7.35 \pm 2.71$ years) and 20 athletes in the control group (mean age, $22.37 \pm 1.24$ years; mean height, $172.53 \pm 8.16$ $\mathrm{cm}$; mean body weight, $71.63 \pm 3.41 \mathrm{~kg}$; and mean training age, $6.83 \pm 2.63$ years).

\subsection{Research Design}

The pre-test measurements of the vertical jump, 30-m speed, agility, and flexibility of the athletes were taken. Subsequently, the 6-week core training program was applied three days a-week, after which the post-test measurements of the athletes were taken. Core training was applied to the training group in addition to football training for 6-week, while the participants in the control group did not apply any training program other than their ongoing football training. Table 1 presents the 15 -min core training program that the participants in the training group applied three days a-week in addition to the normal football training program for 6-week (Turna, 2020). 
Table 1. The applied core training program

\begin{tabular}{|l|l|l|l|}
\hline Movements & $\begin{array}{l}\text { 1/2-Week } \\
\text { Duration/Repetition }\end{array}$ & $\begin{array}{l}\text { 3/4-Week } \\
\text { Duration/Repetition }\end{array}$ & $\begin{array}{l}\text { 5/6-Week } \\
\text { Duration/Repetition }\end{array}$ \\
\hline One Side Plank & $25 \mathrm{~s}-2$ Rep. & $30 \mathrm{~s}-2$ Rep. & $35 \mathrm{~s}-3$ Rep. \\
\hline Elbow Plank & $25 \mathrm{~s}-2$ Rep. & $30 \mathrm{~s}-2$ Rep. & $35 \mathrm{~s}-3$ Rep. \\
\hline V Crunch & $25 \mathrm{~s}-2$ Rep. & $30 \mathrm{~s}-2$ Rep. & $35 \mathrm{~s}-3$ Rep. \\
\hline Leg Drops/Leg Raise & $25 \mathrm{~s}-2$ Rep. & $30 \mathrm{~s}-2$ Rep. & $35 \mathrm{~s}-3$ Rep. \\
\hline Mountain Climbers & $15 \mathrm{~s}-2$ Rep. & $20 \mathrm{~s}-2$ Rep. & $25 \mathrm{~s}-3$ Rep. \\
\hline Scissor Kicks & $25 \mathrm{~s}-2$ Rep. & $30 \mathrm{~s}-2$ Rep. & $35 \mathrm{~s}-3$ Rep. \\
\hline Squat & $20-2$ Rep. & $25-2$ Rep. & $30-3$ Rep. \\
\hline Alternate Superman & $25 \mathrm{~s}-2$ Rep. & $30 \mathrm{~s}-2$ Rep. & $35 \mathrm{~s}-3$ Rep. \\
\hline Glute Bridge & $25 \mathrm{~s}-2$ Rep. & $30 \mathrm{~s}-2$ Rep. & $35 \mathrm{~s}-3$ Rep. \\
\hline Hip Extension & $25 \mathrm{~s}-2$ Rep. & $30 \mathrm{~s}-2$ Rep. & $35 \mathrm{~s}-3$ Rep. \\
\hline
\end{tabular}

\subsection{Data Collection Tools}

\subsubsection{Vertical Jump Test}

A digital jump meter with a $0.1 \mathrm{~cm}$ accuracy was used for vertical jump measurements in the performance tests. After the digital indicator of the jump meter was connected to the waist area and the rope was adjusted, the participant made the jump upward by stretching on his knees. After the jump, the participant tried to fall into the circular plastic area that was connected to the jump meter and placed on the ground. In the event of the participant taking a step forward or backward after landing, the jump was deemed invalid and repeated. The test was carried out twice, and the highest value was recorded in "cm".

\subsubsection{0-Meter Speed Test}

A 30-m sprint test was applied to determine the speed performance of the participants. Photocells were placed at distances of 0 and $30-\mathrm{m}$. Before starting the test, the participants performed a warm-up protocol with 7-min of dynamic stretching and short sprinting after a 10-min warm-up run. The participants performed the test twice, after a 5-min rest interval. The best time of the two attempts was recorded. When the participant was ready, he started from 1-m behind the starting photocell; after reaching the end photocell at a 30-m distance with the highest speed that he could reach, the running time was recorded automatically. The test was carried out twice; and the highest value was recorded in "s".

\subsubsection{Illinois Agility Test}

The 5-m wide, $10-\mathrm{m}$ long test track was prepared by placing three cones with $3.3-\mathrm{m}$ of 
distance between them on a straight line. The test was prepared with a $40-\mathrm{m}$ straight section with $180^{\circ}$ turns every $10-\mathrm{m}$ and a $20-\mathrm{m}$ slalom course between the cones. After the test track was prepared, a two-outlet photocell electronic stopwatch system with an accuracy of $0.01 \mathrm{~s}$ was installed at the beginning and end of the track. The participants were informed about the track before the test and allowed 3-4 trials. Subsequently, the participants were allowed to do 5-min of warm-up and stretching exercises at their own pace. The participants began from the starting line of the test track in a lying-down position facing the ground and with their hands in contact with the ground at a shoulder level. The test was repeated twice with a full rest; and the best result was recorded in "s".

\subsubsection{Sit and Reach Flexibility Test}

The flexibility test measurement of the athletes participating in the study was carried out with a sit and reach test box with a length of $35 \mathrm{~cm}$, a width of $45 \mathrm{~cm}$, and a height of $32 \mathrm{~cm}$. The participants sat on the ground and put their bare feet flat against the test box. The participants then stretched their hands in front of their body as far as they could by bending their torso forward, without bending their knees. The participants waited in this state for 1-2 $\mathrm{s}$ at the farthest point. The test was repeated twice, and the best value was determined in "cm".

\subsection{Analysis of Data}

It was used the SPSS 22 statistics program to evaluate the data and Shapiro-Wilk test to determine the normality distribution of the data. Owing to the normal distribution of the data, it was employed a paired t-test to compare the pre-test and post-test values within the groups. The confidence interval for statistical processes was accepted as $\mathrm{p}<0.05$.

\section{Results}

Table 2. Descriptive statistics showing the age, height, body weight, and training ages of the football players

\begin{tabular}{|l|l|l|l|l|}
\hline Anthropometric Features & Groups & N & Mean & SD \\
\hline \multirow{3}{*}{ Age (years) } & Training & 20 & 21.13 & 1.41 \\
\cline { 2 - 5 } & Control & 20 & 22.37 & 1.24 \\
\hline \multirow{3}{*}{ Height (cm) } & Training & 20 & 174.29 & 7.62 \\
\cline { 2 - 5 } & Control & 20 & 172.53 & 8.16 \\
\hline \multirow{2}{*}{ Body Weight (kg) } & Training & 20 & 70.38 & 4.57 \\
\cline { 2 - 5 } & Control & 20 & 71.63 & 3.41 \\
\hline \multirow{2}{*}{ Training Age (years) } & Training & 20 & 7.35 & 2.71 \\
\cline { 2 - 5 } & Control & 20 & 6.83 & 2.63 \\
\hline
\end{tabular}




\section{MInstitute Macrothink $_{\text {Int }}$}

Table 2 presents values regarding the anthropometric characteristics of the football players in the training and control groups, namely, their age, height, body weight, and training age. The characteristics of the participants in the training group (n: 20) were determined as follows: mean age, $21.13 \pm 1.41$ years; mean height, $174.29 \pm 7.62 \mathrm{~cm}$; mean body weight, $70.38 \pm 4.57$ $\mathrm{kg}$; and mean training age, $7.35 \pm 2.71$ years. In the control group (n: 20), the characteristics were as follows: mean age, $22.37 \pm 1.24$ years; mean height, $172.53 \pm 8.16 \mathrm{~cm}$; mean body weight, $71.63 \pm 3.41 \mathrm{~kg}$; and mean training age, $6.83 \pm 2.63$ years.

Table 3. An in-group comparison of the football players' vertical jump pre-test and post-test values

\begin{tabular}{|l|l|l|l|l|}
\hline Vertical Jump (cm) & Pre-Test & Post-Test & T & P \\
\hline Training Group & $46.32 \pm 6.22$ & $50.61 \pm 6.74$ & -3.86 & $\mathbf{0 . 0 1 *}$ \\
\hline Control Group & $47.46 \pm 7.14$ & $48.53 \pm 6.95$ & -2.12 & 0.78 \\
\hline
\end{tabular}

Note. ${ }^{*} \mathrm{p}<0.05$.

When it was examined the vertical jump pre-test and post-test comparisons within the groups (Table 3), it was found a statistically significant difference in the vertical jump pre-test and post-test values of the training group $(\mathrm{p}<0.05)$. Accordingly, it was determined that the vertical jump post-test values of the training group were significantly higher than the pre-test values. In the control group, there was no statistically significant difference in the vertical jump pre-test and post-test values $(\mathrm{p}>0.05)$.

Table 4. An in-group comparison of the football players' $30-\mathrm{m}$ speed pre-test and post-test values

\begin{tabular}{|l|l|l|l|l|}
\hline 30-m Speed (s) & Pre-Test & Post-Test & T & P \\
\hline Training Group & $4.55 \pm 0.41$ & $4.43 \pm 0.17$ & 0.23 & $\mathbf{0 . 0 2 *}$ \\
\hline Control Group & $4.57 \pm 0.52$ & $4.54 \pm 0.13$ & 0.41 & 0.59 \\
\hline
\end{tabular}

Note. ${ }^{*} \mathrm{p}<0.05$.

When it was analyzed the 30-m speed pre-test and post-test comparisons (Table 4), it was found a statistically significant difference in the $30-\mathrm{m}$ speed pre-test and post-test values of the training group $(\mathrm{p}<0.05)$. Thus, it was determined that the $30-\mathrm{m}$ speed post-test values of the training group were significantly lower than the pre-test values. In the control group, there was no statistically significant difference in the $30-\mathrm{m}$ speed pre-test and post-test values $(\mathrm{p}>$ $0.05)$. 


\section{Macrothink}

Table 5. An in-group comparison of the football players' illinois agility pre-test and post-test values

\begin{tabular}{|l|l|l|l|l|}
\hline Agility (s) & Pre-Test & Post-Test & T & P \\
\hline Training Group & $16.41 \pm 1.38$ & $14.92 \pm 3.11$ & 0.22 & $\mathbf{0 . 0 1 *}$ \\
\hline Control Group & $16.73 \pm 4.06$ & $16.12 \pm 2.34$ & 0.29 & 0.36 \\
\hline
\end{tabular}

Note. ${ }^{*} \mathrm{p}<0.05$.

In Table 5, when it was analyzed the agility pre-test and post-test comparisons, it was found a statistically significant difference in the agility pre-test and post-test values of the training group ( $p<0.05$ ). Accordingly, it was determined that the agility post-test values of the training group were statistically significantly lower than their pre-test values. In the control group, no statistically significant difference was found in the agility pre-test and post-test values $(\mathrm{p}>0.05)$.

Table 6. An in-group comparison of the football players' flexibility pre-test and post-test values

\begin{tabular}{|l|l|l|l|l|}
\hline Flexibility (cm) & Pre-Test & Post-Test & T & P \\
\hline Training Group & $29.27 \pm 6.88$ & $33.46 \pm 7.43$ & -2.51 & $\mathbf{0 . 0 1 *}$ \\
\hline Control Group & $30.18 \pm 7.21$ & $31.35 \pm 6.72$ & -2.17 & 0.28 \\
\hline
\end{tabular}

Note. ${ }^{*} \mathrm{p}<0.05$.

Considering the in-group flexibility pre-test and post-test comparisons in Table 6, a statistically significant difference was found in the flexibility pre-test and post-test values of the training group $(\mathrm{p}<0.05)$. Accordingly, it was determined that the flexibility post-test values of the training group were significantly higher than their pre-test values. In the control group, there was no statistically significant difference in flexibility pre-test and post-test values $(\mathrm{p}>0.05)$.

\section{Discussion}

Considering the results of the study, it was seen that the vertical jump, 30-m speed, agility and flexibility values of the football players in the training group increased after 6-week core training program. When it was reviewed the research that has been conducted to examine the effect of the core training program applied on football players on some performance parameters, it was come across various studies that support the results of this study.

As one of the important results of the study, the 6-week core training program increased the 
vertical jump performance of football players. When studies with similar results are examined, Günay and Onay (1999) stated that two different strength training methods caused a significant increase in anaerobic power values. In a similar study, it was stated that strength training significantly increased the vertical jump values of young football players based on the pre-test and post-test measurements (Gorostiaga et al., 2004). Boyac1 and Afyon (2017) conducted a study on football players between the ages of 12-14 and found that vertical jump performances improved as a result of a 12-week core training program. Similarly, Schiffer et al. (2008) stated that the core training program has a positive effect on the vertical jump performance.

When the studies about the effect of core training on vertical jump performance are examined, the results of this study support previous findings. Core training is also defined as a training method that provides strength increase in the muscles in the lumbopelvic hip area, which is in core stability with the help of exercises performed with body weight (Akman et al., 2013; Clark, 2001). Scientific research indicates that the abdominal muscles are effective in creating the force required for the application of the rotational movement between the hip and back. Kibler et al. (2006) reported that core muscles are effective in achieving abdominal, back, spine and hip stability. In addition, with the development of the core region, the driving muscle strength of the upper extremity increases more. As a result of the study, it is thought that the increase in the vertical jump performance of football players is due to these effects of core training.

As one of the other important results of the research, the 6-week core training program increased the speed performance of the football players. In previous studies in this direction, Balaji and Murugavel (2013) reported that sprint performance, which football players require, improved positively with the core training program. In addition, Boyac1 and Afyon (2017) found that a 12-week core training program improved the performance of football players in the 20-m sprint, vertical jump, and standing long jump. Prieske et al. (2015) stated that an additional 9-week core training program contributed positively to $10-\mathrm{m}$ and $20-\mathrm{m}$ sprint performance. Further, Mendeş (2016) investigated the effect of a 6-week core training program on anaerobic power, sprint, and agility in football and, at the end of the study, observed that the players achieved positive increases in $10-\mathrm{m}$ and $20 \mathrm{-m}$ sprint performance values. Parkhouse et al. (2011) reported that a 6-week static core training program for football players affected their 20-m sprint performance, and Wong et al. (2010) stated that a 12 -week combined core training program, when applied to football players, improved their 20-m speed performance. In addition, Kelly et al. (2011) noted that a 6-week static core training program had a positive contribution to 20-m sprint performance. The results obtained in the aforementioned studies show that basic core stability exercises have a significant effect on the performance development of athletes.

When the studies about the effect of core training on speed performance are examined, the results of this study support previous findings. It is emphasized that with the help of basic exercises, improvement in motoric properties will be achieved. Improved core stability provides an increase in speed, balance and agility performance. Players with improved core stability are able to apply force more efficiently while running and jumping, generate more 
power when hitting a ball, and fight better during play. The increase in sprint performance is thought to be related to the development of muscle mass, as well as the maturation of the nervous system and improved muscular nerve coordination. It is stated that core training not only provides strength gain but also neural adaptation (Iacono et al., 2014). As a result of the study, it is thought that the increase in the speed performance of football players is due to these effects of core training.

According to another result of the research, the 6-week core training program increased the agility performance of the football players. Given the relationship between speed and agility; sprint, acceleration, and agility are considered the most important parameters for determining performance in football (Castagna et al., 2003; Gil et al., 2007). According to the research, young football players who grow older or mature perform better in 10-m and 40-m sprint tests (Le Gall et al., 2010; Buchheit \& Mendez-Villanueva, 2014). However, there are a limited number of investigations on sprint and agility performances, and the results differ in these studies for distances less than 30-m (Papaiakovou et al., 2009). Therefore, it might be concluded that the core strength training program can contribute to sprint performance. However, it is not sufficient to recognize only the basic core training program for anaerobic power and agility measurements. In this context, the relationship between linear sprint and agility performance has been examined in several studies (Little \& Williams, 2005; Vescovi $\&$ Mcguigan, 2008). Paoule et al. (2000) reported that there is a relationship between agility performance and 30-m sprint time in his study with college women. In a different study conducted by Little and Williams (2005), they found a weak relationship between agility performance and 10-m sprint performance in a professional male footballer. The relationship between agility and speed reportedly increases with longer running distances (Vescovi \& Mcguigan, 2008). Moreover, in this context, it is suggested that agility, together with acceleration and speed, represents the most important motor skill of a football player.

High intensity exercises are practiced during a football match as fast acceleration (10-m sprint), maximum speed loads (30-m sprint) or performances that require agility. Agility, which is a basic parameter for maximum performance in many sports, is known as one of the most prominent features among football players. Jones et al. (2009) stated that the increase in sprint performance will increase the agility performance of the football player in the early development period. There are not many studies reporting the effects of core training on agility performance. However, it is thought that agility is particularly related to the speed parameter and agility performance can increase with the development of sprint parameter. According to the results of the study, core training is thought to be effective on agility, especially in terms of strength development and increasing speed performance with neural adaptation. It is concluded that sprint performance improves by increasing strength with core training and this also affects agility performance. In addition, core training increases basic stability and strength by improving the proprioceptive senses and providing muscle development and body control (Iacono et al., 2014). As a result of the study, it is thought that the increase in the agility performance of football players is due to these effects of core training.

In another of the results obtained in the study, the 6-week core training program increased the 


\section{Macrothink}

flexibility performance of the football players. In previous studies, Eler and Sevim (2002), in a study that investigated a handball-specific core strength training program in relation to certain performance parameters, indicated that the flexibility values of the training group increased significantly. Şahin (2008) examined the effects of two different strength training programs on some physical, physiological, and technical properties and stated that there was a significant increase in the flexibility values of the rapid strength and strength continuity group among the groups participating in the study. Similarly, in another study, Akcan (2013) reported that two different strength training programs that were applied to male athletes caused a significant increase in the flexibility values of training group athletes.

When the studies about the effect of core training on flexibility performance are examined, the results of this study support previous findings. Some certain characteristics of the individuals, such as age, height and weight, have been known to affect flexibility rates. Ergun and Baltac1 (1992) observed a negative correlation between the flexibility and body weight in their study. Accordingly, flexibility is increased with decreasing body weight. With core training, muscle mass increases and the percentage of body fat decreases in parallel. With the increase in muscle mass, the decreasing body fat ratio affects the total body weight. As a result of the study, it is thought that the increase in the flexibility performance of football players is due to these effects of core training.

\section{Conclusion}

Therefore, as per the results of these studies, the core training program has a positive effect on some performance parameters. Based on the results of the present research, the 6-week core training program that was applied to football players improved the performance of vertical jump, 30-m speed, agility, and flexibility. Core training can be used for performance purposes because it is a type of strength exercise that does not require weights; the individual can exercise with their body weight. It is thought that applying core exercises as a standalone training program or including them in training planning to cover a certain part of the training program will prove beneficial in terms of performance improvement.

\section{References}

Afyon, Y. A. (2014). Effect of core training on 16-year-old soccer players. Educational Research and Reviews, 9(23), 1275-1279.

Akcan, F. (2013). Effect of two different strength training programs applied to male athletes in various branches on physical and physiological properties. Gaziantep: Gaziantep University, Institute of Health Sciences.

Akman, T., Kabadayı, M., Elioz, M., Cilhoroz, B., \& Akyol, P. (2013). Effect of jogging and core training after supramaximal exercise on recovery. Turkish Journal of Sport and Exercise, 15(1), 73-77.

Akyüz, M., Uzaldi, B. B., Akyüz, Ö., \& Doğru, Y. (2016). Comparison of sprint reaction and visual reaction times of athletes in different branches. Journal of Education and Training Studies, 5(1), 94-100. https://doi.org/10.11114/jets.v5i1.1987 
Balaji, E., \& Murugavel, K. (2013). Motor fitness parameters response to core strength training on handball players. International Journal for Life Sciences and Educational Research, 1(2), 76-80.

Boyac1, A., \& Afyon, Y. A. (2017). The effect of the core training to physical performance in children. Journal of Education and Practice, 8(33), 81-88.

Boyle, M. (2004). Functional training for sports. England: Human Kinetics Publishers.

Buchheit, M., \& Mendez-Villanueva, A. (2014). Effects of age, maturity and body dimensions on match running performance in highly trained under-15 soccer players. $J$ Sports Sci, 32(13), 1271-1278. https://doi.org/10.1080/02640414.2014.884721

Castagna, J. B., D’Ottavio, S., \& Abt, G. (2003). Activity profile of young soccer players during actual match play. J Strength Cond Res, 17, 775-780. https://doi.org/10.1519/ 00124278-200311000-00024

Clark, M. A. (2001). Core stabilization training in rehabilitation. Techniques in musculoskeletal rehabilitation (pp. 259-278). Prentice, New York.

Dello, I. A., Padulo, J., \& Ayalon, M. (2016). Core stability training on lower limb balance strength. Journal of Sports Sciences, 34(7), 671-678. https://doi.org/10.1080/02640414. 2015.1068437

Eler, S., \& Sevim, Y. (2002). Investigation of the effects of handball-specific strength training on some performance parameters of young male handball players (p. 62). Paper presented at the 7th International Sport Sciences Congress, Antalya.

Eniseler, N. (1994). Physiological factors affecting football. Journal of Football Science and Technology, 1(1), 10-12.

Ergun, N., \& Baltac1, G. (1992). The relationship between static strength measurements and physical properties in elite athletes according to age and gender. HU Journal of Sports Science, 3, 3-10.

Faries, M. D., \& Greenwood, M. (2007). Core training: Stabilizing the confusion. Strength and Conditioning Journal, 29(2), 10. https://doi.org/10.1519/00126548-200704000-00001

Gil, S., Ruiz, F., Irazusta, A., Gil, J., \& Irazusta, J. (2007). Selection of young soccer players in terms of anthropometric and physiological factors. $J$ Sport Med Phys Fit, 47, 25-32.

Gorostiaga, E. M., Izquierdo, M., Ruesta, M., Iribarren, J., Gonzalez-Badillo, J. J., \& Ibanez, J. (2004). Strength training effects on physical performance and serum hormones in young soccer players. Eur J Appl Physiol, 91, 698. https://doi.org/10.1007/s00421-003-1032-y

Günay, M., \& Onay, M. (1999). Effects of progressive resistance exercises and maximal strength exercises on strength development, resting heart rate, blood pressure, aerobic-anaerobic power and body composition. Gazi Univ J Phys Educ Sport Sci., 4(4), 21-31. 
Handzel, T. M. (2003). Core training for improved performance. NSCA's Performance Training Journal, 2(6), 26-30.

Iacono, A. D., Martone, D., Alfieri, A., Ayalon, M., \& Buono, P. (2014). Core stability training program (CSTP) effects on static and dynamic balance abilities. Gazzetta Medica Italiana Archivio per le Scienze Mediche, 173(4), 197-206.

Jones, P., Bampouras, T. M., \& Marrin, K. (2009). An investigation into the physical determinants of change of direction speed. J Sport Med Phys Fit, 49, 97-104.

Kelly, L., Parkhouse, K. L., \& Nick, B. (2011). Influence of dynamic versus static core exercises on performance in field-based fitness tests. Journal of Body Work and Movement Therapies, 15(4), 517-524. https://doi.org/10.1016/j.jbmt.2010.12.001

Kibler, W. B., Press, J., \& Sciascia, A. (2006). The role of core stability in athletic function. Sports Medicine, 36(3), 189-198. https://doi.org/10.2165/00007256-200636030-00001

Köklü, Y., Özkan, A., Alemdaroğlu, U., \& Ersöz, G. (2009). The comparison of some physical fitness and somatotype characteristics of young soccer players according to their playing positions. Spormetre Journal of Physical Education and Sports Science, 7(2), 61-68.

Köse, B., \& Atl1, A. (2020). Investigation of the effect of high intensity interval training on agility speed and aerobic performance in young soccer players. Turkish Journal of Sports Sciences, 4(1), 61-68. https://doi.org/10.32706/tusbid.730085

Le Gall, F., Carling, C., Williams, M., \& Reilly, T. (2010). Anthropometric and fitness characteristics of international, professional and amateur male graduate soccer players from an elite youth academy. J Sci Med Sports, 13, 90-95. https://doi.org/10.1016/j.jsams. 2008.07.004

Little, T., \& Williams, A. (2005). Specificity of acceleration, maximum speed and agility in professional soccer players. J Strength Cond Res, 19, 76-78. https://doi.org/10.1519/ 00124278-200502000-00013

McGill, S. (2010). Core training: Evidence translating to better performance and injury prevention. Strength and Conditioning Journal, 32(3), 33-46. https://doi.org/10.1519/SSC. 0b013e3181df4521

Mendes, B. (2016). The effects of core training applied to footballers on anaerobic power, speed and agility performance. Anthropologist, 23(3), 361-366. https://doi.org/10.1080/0972 0073.2014 .11891956

Muratl1, S. (2007). Children and sports. Ankara: Nobel Publisher.

Paoule, K., Madole, K., Garhammer, J., Lacourse, M., \& Rozenek, R. (2000). Reliability and validity of the t-test as a measure of agility, leg power and leg speed in college-aged men and women. J Strength Cond Res, 14, 443-450. https://doi.org/10.1519/00124278-20001100000012

Papaiakovou, G., Giannakos, A., \& Michailidis, C. (2009). The effect of chronological age 
and gender on the development of sprint performance during childhood and puberty. $J$ Strength Cond Res, 23, 2568-2573. https://doi.org/10.1519/JSC.0b013e3181c0d8ec

Parkhouse, K. L., \& Ball, N. (2011). Influence of dynamic versus static core exercises on performance in field-based fitness tests. Journal of Bodywork and Movement Therapies, 15(4), 517-524. https://doi.org/10.1016/j.jbmt.2010.12.001

Prieske, O., Muehlbauer, T., Borde, R., Gube, M., Bruhn, S., Behm, D. G., \& Granacher, U. (2015). Neuromuscular and athletic performance following core strength training in elite youth soccer: Role of instability. Scandinavian Journal of Medicine and Science in Sports, 26(1), 48-56. https://doi.org/10.1111/sms.12403

Riewald, S. T. (2003). Training the "other core". Performance Training Journal, 2(3), 5-6.

Saeterbakken, A. H., Van den Tillaar, R., \& Seiler, S. (2011). Effect of core stability training on throwing velocity in female handball players. The Journal of Strength and Conditioning Research, 25(3), 712-718. https://doi.org/10.1519/JSC.0b013e3181cc227e

Şahin, G. (2008). The effects of two strength training programs applied to 17-19 years-old top level male field hockey players on physical, physiological, and technical parameters. Ankara: Gazi University, Institute of Health Sciences.

Sato, K., \& Mokha, M. (2009). Does core strength training influence running kinetics, lower-extremity stability, and 5000-m performance in runners? The Journal of Strength and Conditioning Research, 23(1), 133-140. https://doi.org/10.1519/JSC.0b013e31818eb0c5

Schiffer, T., Schulte, S., \& Sperlich, B. (2008). Aerobic dance: Health ve fitness effects in middle aged premenopausal women. Journal of Exercise Physiology Online, 11(4), 25-33.

Stanton, R., Reaburn, P. R., \& Humphries, B. (2004). The effect of short-term swiss ball training on core stability and running economy. The Journal of Strength and Conditioning Research, 18(3), 522-528. https://doi.org/10.1519/00124278-200408000-00023

Sun, X., Gao, Q., Dou, H., \& Tang, S. (2016). Which is better in the rehabilitation of stroke patients, core stability exercises or conventional exercises? Journal of Physical Therapy Science, 28(4), 1131-1133. https://doi.org/10.1589/jpts.28.1131

Tatlıcı, A., Çakmakçı, E., Yılmaz, S., \& Arslan, F. (2018). Comparison of visual reaction values of elite deaf wrestlers and elite normally hearing wrestlers. Turkish Journal of Sport and Exercise, 20(2), 63-66. https://doi.org/10.15314/tsed.440813

Turna, B. (2020). The effects of 6-week core training on selected biomotor abilities in soccer players. Journal of Education and Learning, 9(1), 99. https://doi.org/10.5539/jel.v9n1p99

Ünlü, G., \& Tatlıc1, A. (2018). The acute effects of proprioceptive neuromuscular facilitation (PNF) stretching on dynamic balance performance in elite wrestlers. J Sport Educ Sci, 5, 57-63.

Vescovi, J. D., \& Mcguigan, M. R. (2008). Relationships between sprint, agility and jump ability in female athletes. J Sports Sci, 26(1), 97-107. https://doi.org/10.1080/02640410701 
348644

Wong, P. L., Chamari, K., \& Wisloff, U. (2010). Effects of 12-week on field combined strength and power training on physical performance among U-14 young soccer players. $J$ Strength Cond Res, 24(3), 644-652. https://doi.org/10.1519/JSC.0b013e3181ad3349

\section{Copyright Disclaimer}

Copyright for this article is retained by the author(s), with first publication rights granted to the journal.

This is an open-access article distributed under the terms and conditions of the Creative Commons Attribution license (http://creativecommons.org/licenses/by/3.0/). 